\title{
Child passenger safety: potential impact of the Washington State booster seat law on childcare centers
}

\author{
B A Chang, B E Ebel, F P Rivara
}

Injury Prevention 2002;8:284-288

See end of article for authors' affiliations

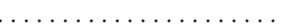

Correspondence to: Brittany Chang, Department of Pediatrics, Box 359774, Harborview Medical Center, 325 9th Avenue, Seattle, WA 98104-2499, USA; changba@u.washington.edu

\begin{abstract}
Objectives: To examine factors associated with compliance and with perceived readiness for the new Washington State booster seat law, and to identify perceived barriers to compliance among licensed childcare centers.

Design/methods: Surveys were mailed to a random sample of 550 licensed childcare centers in Washington State, approximately nine months before the law was to go into effect.

Results: Only $18 \%$ of centers reported being compliant with the law at the time of the survey. Factors associated with current compliance included awareness and knowledge of the law, and being comfortable asking staff and parents to use booster seats. A lack of center-owned booster seats was associated with a lower likelihood of compliance. Only $43 \%$ of centers had already started preparing for the law, and only $48 \%$ believed they would definitely be ready in time.

Conclusion: This study suggests that Washington State childcare centers need support and assistance to increase their knowledge of booster seats and reduce the financial costs of compliance.
\end{abstract}

$\mathrm{B}$ elt positioning booster seats can decrease the risk of serious injury in a car crash for children who have outgrown child harness seats, but who cannot yet safely use adult lap-shoulder belts. ${ }^{1}$ However, recent research has indicated that 4-8 year old children are often prematurely moved from child car seats into adult lap-shoulder belts that do not fit them properly, and thus remain at high risk of death or serious injury in a car crash. ${ }^{2}$

On 9 March 2000, Washington State passed the nation's first law (Booster Law) requiring that children between 4 and 6 years of age, and $40-60$ pounds $(18-27 \mathrm{~kg})$, use a booster seat when riding in a motor vehicle. ${ }^{3}$ The new law took effect on I July 2002 and is subject to primary enforcement, meaning that a vehicle can be stopped and the driver ticketed solely for an inappropriately restrained child. Although the law does not contain specific provisions for childcare centers, those that transport children on field trips must comply. School buses are exempt from the law, and childcare providers are not accountable for transportation outside of center-sponsored trips, including pick-up and drop-off.

This report is part of a study designed to examine the impact of the new booster seat legislation on Washington State childcare providers in order to determine their response to the law, and to inform the development of safety messages aimed at increasing booster seat use. Our study objectives included identification of factors associated with current compliance to the booster seat law, identification of factors related to perceived readiness for the law, and an analysis of perceived barriers, help needed, and other predictors of compliance. We hypothesized that childcare centers transporting children on field trips and professing a higher degree of comfort and knowledge regarding the booster seat law would be more likely to be ready for the new law, and more likely to be currently compliant with the new law.

\section{METHODS}

\section{Study design}

We obtained a comprehensive list of all licensed childcare centers in Washington State $(n=1865)$ from Washington Child Care Resource and Referral Network agencies. Unlicensed childcare is illegal in Washington State and anyone providing regular, on-going childcare must be licensed. ${ }^{4} \mathrm{~A}$ sample of 550 centers was randomly selected. Incorporating techniques proven to increase response rate, ${ }^{5}$ we developed a brief survey to determine how childcare providers were responding to the new booster seat law $1 \frac{1 / 2}{2}$ years after it was enacted, and approximately nine months before it went into effect. A multiple choice structure was chosen to increase the consistency of information across the sample, as well as improve the response rate. ${ }^{6}$ Survey questions were based on phase four of Green and Kreuter's PRECEDE-PROCEED model of health promotion, which provides an educational and ecological framework of factors that influence behaviors. ${ }^{7}$ Answer choices were derived from previous research examining factors related to booster seat non-use. ${ }^{89}$ Only limited information regarding the booster seat law was included so as not to bias response. An attached cover letter explained the study purpose and assured confidentiality. No identifying information was solicited, and data were analyzed using study identification numbers only.

Surveys were addressed and mailed to childcare center directors using a three phase mailing process. ${ }^{6}$ An initial mailing was sent to all 550 childcare centers in September 2001. The mailing included the survey and a postage paid return envelope, as well as a $\$ 1$ incentive, an informational booster seat brochure, a discount booster coupon, and an order form for additional materials. Second and third mailings were sent to all non-respondents in October and November 2001.

The study was approved by the University of Washington Institutional Review Board.

\section{Measures}

Self reported compliance with the law and perceived readiness-to-comply were designated as dependent variables of interest. A respondent was categorized as currently compliant if s/he checked the category: "already comply with the law" on the survey. Readiness-to-comply was determined by asking providers "On a scale of 1 to 6 , how likely is it that your

Abbreviations: $\mathrm{Cl}$, confidence interval; $\mathrm{OR}$, odds ratio, $\mathrm{RUCAs}$, rural-urban commuting area codes 


\begin{tabular}{|c|c|c|}
\hline & $\%$ (No) & $95 \% \mathrm{Cl}$ \\
\hline \multicolumn{3}{|l|}{ Location of childcare center $(n=357)$} \\
\hline Urban & 85 (304) & 81 to 89 \\
\hline Rural & $15(53)$ & 11 to 19 \\
\hline \multicolumn{3}{|l|}{ Position of respondent $(n=351)$} \\
\hline Childcare center director & $72(252)$ & 64 to 77 \\
\hline Childcare center staff & $9(32)$ & 6 to 12 \\
\hline Other position & $19(67)$ & 15 to 24 \\
\hline \multicolumn{3}{|l|}{ Transport children $(n=320)$} \\
\hline Do transport children in vehicles on field trips & $70(223)$ & 64 to 75 \\
\hline Do not transport children in vehicles on field trips & 30 (97) & 25 to 35 \\
\hline \multicolumn{3}{|l|}{ Awareness $(n=344)$} \\
\hline Aware of the new booster seat law & $74(255)$ & 69 to 79 \\
\hline Not aware of the new booster seat law & $26(89)$ & 21 to 31 \\
\hline \multicolumn{3}{|l|}{ Compliance among transporting centers $(n=223)$} \\
\hline Already comply with the booster seat law & $18(40)$ & 13 to 23 \\
\hline Not yet in compliance with the law & $82(183)$ & 77 to 87 \\
\hline \multicolumn{3}{|l|}{ Self efficacy $(n=339)$} \\
\hline Comfortable asking staff and parents to use booster seats & $72(245)$ & 67 to 77 \\
\hline Not comfortable asking staff and parents to use booster seats & $28(94)$ & 23 to 33 \\
\hline \multicolumn{3}{|l|}{ Preparation $(n=295)$} \\
\hline Center is currently preparing for the new law & $43(127)$ & 37 to 49 \\
\hline Center is not yet preparing for the new law & $57(168)$ & 51 to 63 \\
\hline \multicolumn{3}{|l|}{ Readiness $(n=325)$} \\
\hline Center will definitely be ready for the law by 1 July 2002 & $48(156)$ & 43 to 53 \\
\hline Center will not be ready for the law by 1 July 2002 & 52 (169) & 47 to 57 \\
\hline
\end{tabular}

childcare center will be ready for the new booster seat law by July 1, 2002?", with 1 being "very unlikely to be ready", and 6 being "will definitely be ready". Descriptors were attached to end points only. Respondents endorsing points 1 through 5 were categorized as "not ready", while those who checked 6 were categorized as "ready". Responses were collapsed because we saw readiness as an absolute, in that a center was either ready or was not ready for the law. Providing an expanded scale also served to increase accuracy, as providers may have been reluctant to reveal that they were not ready. Other compliance related characteristics assessed included perceived barriers, current preparations for the law, and help needed to comply.

Self efficacy has been found to be an important determinant in behavior change. ${ }^{10}$ We measured providers' self efficacy, or their confidence in affecting change, by asking providers to rank how comfortable they were requesting staff and parents to use booster seats. Descriptors were attached to each point on a Likert scale and ranged from "very comfortable" to "very uncomfortable". Replicating the method described above, respondents endorsing "very comfortable" were classified as comfortable, and all others were classified as uncomfortable.

Rural and urban categorizations were based on the 1990 rural-urban commuting area codes (RUCAs). ${ }^{11}$ We designated codes for metropolitan areas through large towns (RUCAs 1-6) as urban, and those for small towns through rural areas (RUCAs 7-10) as rural.

\section{Data analysis}

Survey responses were double key entered and analyzed using STATA version 7.0. ${ }^{12}$ Bivariate logistic regression was used to determine associations between the current compliance and readiness to comply variables with other childcare center characteristics. Variables with significant associations were included in subsequent multivariate logistic regression models using a stepwise regression model with probability of entry $=0.05$, and probability of removal $=0.10$.

Descriptive statistics, including frequencies and median values when appropriate, were calculated to examine childcare center characteristics and to compare the study sample with the list of all licensed childcare providers in Washington State.

\section{RESULTS}

\section{Childcare center characteristics}

A total of 550 surveys were mailed, and 357 were returned, for a final response rate of $65 \%$. Center capacity and rural/urban location of responding and non-responding centers were similar to each other and to those in the statewide database (data not shown). The median number of 4-6 year olds enrolled at each responding center was 23 children.

The majority of survey respondents identified themselves as childcare center directors (table 1), and most centers reported transporting children in vehicles for field trips. At the time of the survey only $43 \%$ (127) of centers had already started preparing for the new law, and only $48 \%$ (156) believed that they would definitely be ready by the time it went into effect on I July 2002. Though 70\% (255) of respondents were aware of the law and felt comfortable asking staff and parents to use booster seats, only 18\% (40) of transporting centers reported being currently compliant with the law.

Among respondents who were aware of the Booster Law, most had heard about it on television or radio $(36 \%)$, or by receiving information in the mail $(35 \%)$. Childcare center newsletters (29\%) and newspapers were also commonly mentioned sources of information (26\%), while the internet and bus advertisements were rarely mentioned as sources of information.

\section{Current compliance}

Among transporting childcare centers reporting current compliance, most had achieved compliance by asking parents to provide booster seats for field trips $(87 \% n=35)$. Only $35 \%$ of providers were able to purchase booster seats for use as permanent center equipment $(n=13)$. Twelve percent of centers had complied with the law by stopping field trips for their center $(n=5)$. Half of respondents required booster seats for pick-up, drop-off, and carpools $(n=20)$.

\section{Factors associated with current compliance}

Bivariate regression analysis indicated that childcare providers who were aware of the Booster Law were more likely to be compliant (table 2). Providers who were comfortable asking parents and staff to use booster seats were twice as likely to be compliant (odds ratio (OR) 2.6; 95\% confidence interval (CI) 
Table 2 Factors associated with current compliance with the law

\begin{tabular}{|c|c|c|c|c|c|c|c|c|}
\hline & \multirow{2}{*}{$\begin{array}{l}\% \text { (No) } \\
\text { within } \\
\text { compliant } \\
\text { centers }\end{array}$} & \multirow{2}{*}{$\begin{array}{l}\% \text { (No) within } \\
\text { non-compliant } \\
\text { centers }\end{array}$} & \multicolumn{3}{|c|}{ Univariate } & \multicolumn{3}{|c|}{ Multivariate } \\
\hline & & & OR & $95 \% \mathrm{Cl}$ & No & $\begin{array}{l}\text { Adjusted } \\
\text { OR* }\end{array}$ & $95 \% \mathrm{Cl}$ & No \\
\hline \multicolumn{9}{|l|}{ Childcare center characteristics } \\
\hline Center currently transports children & $78(43)$ & $68(26)$ & 1.7 & 0.8 to 3.5 & 320 & 2.7 & 1.2 to 6.1 & 310 \\
\hline$>$ Twenty $4-6$ year olds enrolled $\dagger$ & $44(40)$ & $54(183)$ & 0.7 & 0.4 to 1.2 & 357 & & & \\
\hline Urban location $\ddagger$ & 83 (23) & $86(163)$ & 0.8 & 0.4 to 1.8 & 357 & & & \\
\hline \multicolumn{9}{|l|}{ Respondent characteristics } \\
\hline Respondent is director $\S$ & $65(43)$ & $74(202)$ & 1.6 & 0.6 to 4.4 & 351 & & & \\
\hline Heard about the law in 2 or more places & $46(48)$ & 32 (207) & 1.8 & 1.0 to 3.3 & 357 & & & \\
\hline Aware of law & 94 (33) & $71(221)$ & 6.6 & $\begin{array}{l}2.0 \text { to } \\
21.9\end{array}$ & 344 & 4.5 & $\begin{array}{l}1.3 \text { to } \\
15.2\end{array}$ & 310 \\
\hline $\begin{array}{l}\text { Comfortable asking staff and parents to use booster } \\
\text { seats } \uparrow\end{array}$ & $86(24)$ & $70(98)$ & 2.6 & 1.1 to 6.1 & & 2.4 & 1.0 to 5.7 & 310 \\
\hline \multicolumn{9}{|l|}{ Barriers to compliance } \\
\hline Lack of booster seats owned by the center & $21(11)$ & 45 (138) & 0.3 & 0.2 to 0.7 & 357 & 0.23 & $\begin{array}{l}0.08 \text { to } \\
0.69\end{array}$ & 310 \\
\hline Lack knowledge about law & $8(8)$ & $30(42)$ & 0.2 & 0.1 to 0.5 & 357 & 0.23 & $\begin{array}{l}0.11 \text { to } \\
0.51\end{array}$ & 310 \\
\hline Staff unclear about proper seat use & $8(11)$ & $16(72)$ & 0.5 & 0.2 to 1.3 & 357 & & & \\
\hline Not enough cars to that fit boosters & $15(11)$ & $14(83)$ & 1.1 & 0.5 to 2.6 & 357 & & & \\
\hline Perceived parent resistance to using booster seats & $21(4)$ & $24(48)$ & 0.9 & 0.4 to 1.8 & 357 & & & \\
\hline Perceived child resistance to using booster seats & $6(3)$ & $9(27)$ & 0.6 & 0.2 to 2.2 & 357 & & & \\
\hline Lack of storage space for booster seats during the day & $21(4)$ & $28(93)$ & 0.7 & 0.4 to 1.5 & 357 & & & \\
\hline
\end{tabular}

*Adjusted for awareness of law, lack of knowledge about the law, lack of boosters owned by center, and comfort asking staff and parents to use boosters. Reference categories are: †center has = twenty 4-6 year olds enrolled, frural location, §respondent is other than childcare center director, Inot comfortable asking staff and parents to use booster seat.

1.1 to 6.1). Providers who indicated a lack of knowledge about the law were significantly less likely to comply (OR 0.2; 95\% CI 0.1 to 0.5$)$. Those who identified a lack of center-owned booster seats as a barrier were also less likely to comply (OR $0.3 ; 95 \%$ CI 0.2 to 0.7 ). Correlation between awareness and lack of knowledge was low, perhaps because providers may have been generally aware of the Booster Law, while lacking good knowledge about how the law applied to their children or the vehicles used by their center.

In the multivariate regression model, significant predictors of center compliance were: whether or not a center transports children on field trips, awareness of the law, lack of knowledge about the law, and lack of center-owned booster seats.

There were no significant associations between compliance and other childcare center characteristics such as urban or rural location or the number of 4-6 year old children enrolled.

\section{Methods of preparation for the Booster Law}

Among transporting childcare providers who did not believe themselves to be already in compliance, but had reportedly already started preparing for the new law $(n=98), 56 \%$ had done so by handing out booster seat brochures to parents and childcare staff. Thirty nine percent had started preparing by including information about the new law in their childcare center newsletter. Methods requiring a greater use of resources, such as revising transportation policies, attending training courses, and purchasing extras seats for the center were less common methods of preparation.

\section{Barriers to compliance}

We asked childcare providers to describe the types of challenges they believe will inhibit their ability to adhere to the Booster Law. Barriers related to knowledge and implementation factors were most frequently cited. The most widely mentioned challenge to compliance was a lack of boosters owned by the center $(62 \%)$, followed by a limited storage space for the extra booster seats $(38 \%)$, and a lack of knowledge about the law (31\%). More than a quarter $(27 \%)$ of childcare centers felt that parent resistance to using booster seats would be a barrier to compliance, and approximately one fifth of responding centers felt that they lacked access to enough vehicles that would fit boosters. Respondents also gave open responses specifically mentioning a lack of money to purchase seats, a lack of proper enforcement, and a lack of staff to help load/unload seats as additional barriers to compliance.

Factors associated with perceived readiness for the law In order to determine the salient issues for childcare centers regarding their ability to comply with the Booster Law, we also examined factors associated with whether or not they believed they would be ready for the law by the 1 July 2002 enactment date (table 3). Providers who were comfortable asking staff and parents to use booster seats were nearly three times as likely to believe they would be ready in time for the law (OR $2.8 ; 95 \%$ CI 1.6 to 4.8 ). Conversely, centers reporting that they lacked booster seats were less likely to report they would be ready (OR 0.5 ; 95\% CI 0.3 to 0.7 ) in time. There was a marginally significant relationship between perceived readiness and whether centers indicated they had access to vehicles that accommodate booster seats (OR 0.6 ; 95\% CI 0.3 to 1.0 ). Adjusting for significant predictors of readiness in the multivariate logistic model, we found that perceived readiness was positively associated with respondents who felt comfortable advocating booster seat use to staff and parents, and was negatively associated with centers in which a lack of center-owned seats presented a challenge to compliance. There were no significant associations between perceived readiness and childcare center characteristics, including urban or rural location, whether or not the center transports children, and number of 4-6 year olds enrolled.

\section{Help needed for compliance}

Ninety one percent (325) of responding childcare centers indicated that they would need assistance in order to be ready for the Booster Law. The most commonly cited forms of help needed for compliance were coupons for discounted booster seats $(75 \%)$, and informational brochures for staff and parents $(65 \%)$. Twenty eight percent of centers wanted more information and a better understanding of the law, and $21 \%$ wanted information on booster seat resources or programs. Less frequently mentioned forms of help included data on motor vehicle injuries (18\%), and booster seat training courses 
Table 3 Factors associated with perceived readiness

\begin{tabular}{|c|c|c|c|c|c|c|c|c|}
\hline & \multirow{2}{*}{$\begin{array}{l}\%(\mathrm{No}) \\
\text { within ready } \\
\text { centers }\end{array}$} & \multirow{2}{*}{$\begin{array}{l}\%(\mathrm{No}) \\
\text { within not } \\
\text { ready } \\
\text { centers }\end{array}$} & \multicolumn{3}{|c|}{ Univariate } & \multicolumn{3}{|c|}{ Multivariate } \\
\hline & & & OR & $95 \% \mathrm{Cl}$ & No & $\begin{array}{l}\text { Adjusted } \\
\text { OR* }^{*}\end{array}$ & $95 \% \mathrm{Cl}$ & No \\
\hline \multicolumn{9}{|l|}{ Childcare center characteristics } \\
\hline Urban location $†$ & 85 (132) & $88(148)$ & 0.8 & 0.4 to 1.8 & 325 & & & \\
\hline Center currently transports children & $69(102)$ & 73 (1 1 12) & 1.7 & 0.8 to 3.5 & 300 & & & 296 \\
\hline$>$ Twenty 4-6 year olds enrolled $\ddagger$ & $51(79)$ & $55(93)$ & 0.7 & 0.4 to 1.2 & 324 & & & \\
\hline \multicolumn{9}{|l|}{ Respondent characteristics } \\
\hline $\begin{array}{l}\text { Comfortable asking staff and parents to use booster } \\
\text { seats } \S\end{array}$ & $84(128)$ & $65(110)$ & 2.8 & 1.6 to 4.8 & 320 & 2.7 & 1.6 to 4.8 & 296 \\
\hline Aware of law & $78(118)$ & $74(125)$ & 1.2 & 0.7 to 2.0 & 320 & & & \\
\hline Respondent is center director $\mathbb{T}$ & 72 (111) & 47 (124) & 0.9 & 0.5 to 1.6 & 323 & & & \\
\hline Heard about the law in 2 or more places & $35(55)$ & $37(62)$ & 0.9 & 0.6 to 1.5 & 325 & & & \\
\hline \multicolumn{9}{|l|}{ Perceived barriers to compliance } \\
\hline Lack of booster seats owned by the center & $35(54)$ & $54(91)$ & 0.5 & 0.3 to 0.7 & 325 & 0.5 & 0.31 to 0.8 & 296 \\
\hline Lack of access to enough cars to that fit booster seats & $12(18)$ & $19(32)$ & 0.6 & 0.3 to 1.0 & 325 & & & 296 \\
\hline Perceived parent resistance to using seats & $21(33)$ & $27(45)$ & 0.7 & 0.4 to 1.2 & 325 & & & \\
\hline Lack of storage space for booster seats during the day & $26(40)$ & $31(53)$ & 0.8 & 0.4 to 1.2 & 325 & & & \\
\hline Staff unclear about proper seat use & $13(21)$ & $17(29)$ & 0.8 & 0.4 to 1.4 & 325 & & & \\
\hline Perceived child resistance to using seats & $8(12)$ & $10(17)$ & 0.7 & 0.3 to 1.6 & 325 & & & \\
\hline Lack of knowledge about the new law & $28(44)$ & $30(49)$ & 1.0 & 0.6 to 1.5 & 325 & & & \\
\hline
\end{tabular}

*Adjusted for lack of booster seats owned by center, comfortable asking staff and parents to use boosters, and lack of access to cars that fit boosters. Reference categories are: †rural location, łcenter has = twenty 4-6 year olds enrolled, §not comfortable asking staff and parents to use booster seats, Irespondent is other than childcare center director.

(12\%). Four percent wrote in that they needed money for seats and training.

Childcare providers were asked where they preferred to receive information about child safety. Fifty five percent favored the state licensing board, followed by health professionals (54\%), and continuing education classes (49\%). Television and radio were also frequently mentioned sources of child safety information $(28 \%)$, as were parenting magazines $(23 \%)$.

\section{DISCUSSION}

This study indicates that while most childcare centers were aware of the new Washington State booster seat legislation, most will need help with the costs of compliance and an increased understanding of the law for adequate adherence. Factors that were associated with compliance included awareness of and knowledge about the law, being comfortable asking staff and parents to use booster seats, and feeling that a lack of center-owned booster seats presented a barrier to compliance. Other frequently mentioned challenges to compliance included insufficient storage space for booster seats during the day as well as inadequate knowledge about the law. Booster seat safety education with childcare centers should address these implementation and knowledge barriers.

Our finding that childcare providers lacked sufficient knowledge about the law is commensurate with recent research suggesting that parents also receive ambiguous messages about when their child should use a booster seat. ${ }^{8}$ Some of this confusion may stem from the discrepancy between Washington State law, which mandates booster seat use from 4-6 years and 40-60 pounds (18-27 kg), and National Highway Traffic Safety Administration recommendations extending the range of appropriate use to 4-8 years and 40-80 pounds $(18-36 \mathrm{~kg}) .{ }^{13}$ Likewise, childcare providers who lack basic knowledge about the law and related safety guidelines may not feel comfortable asking parents and staff to use booster seats. Therefore, effective promotion materials must explain the law, and address weight and age guidelines in clear, consistent terms. Materials should also clarify enforcement, and explain exemptions for school buses and large passenger vans.

Successful booster seat promotions will need to address financial costs of compliance. Nearly half of all respondents (154) requested booster seat discount coupons and materials from us, perhaps reflecting both the necessity to defray costs and to get additional clarification about the law. Failing to address costs could result in an inequitable impact of the law on centers with insufficient resources. As was indicated by this study, centers without the ability to obtain affordable seats may be faced with the difficult choice of stopping field trips. To mitigate financial barriers, successful outreach campaigns could provide coupons and bulk buying programs for discounted booster seats.

Legislation is another effective injury prevention tool, and previous research has found that changes to childcare center transportation policies can serve to reinforce car safety messages and increase saliency to parents. ${ }^{14}$ Effective promotion efforts should encourage both transporting and nontransporting childcare centers to promote booster safety, and model appropriate usage through childcare center transportation policies.

Providers identified the state childcare licensing board and healthcare professionals as their most preferred sources of child safety information. Booster seat education involving these agents, as well a messages promoted through television and radio, may be most effective in facilitating childcare center compliance with the law.

\section{Limitations}

There are several potential limitations. First, while this study provided valuable information regarding childcare centers' perspectives of the new booster seat law, only licensed childcare centers were surveyed. Licensed family homes were excluded from the sample because $70 \%$ of children in licensed care in Washington State are cared for in centers, ${ }^{15}$ and we believed that the smaller family homes would be unlikely to transport children. Second, other than address and zip code, we did not obtain demographic information from responding childcare centers, limiting our ability to judge non-response bias and to judge the significance of socioeconomic context in predicting center compliance. Third, the validity of the data is subject to errors of response inherent in self reports, and it is possible that childcare providers over-reported perceived readiness, current compliance, or readiness for the law, in efforts to cast their center in a favorable light. Fourth, interpretation is limited by small number of centers that were currently compliant with the law, leading to small sample sizes in some categories. Lastly the $65 \%$ of centers that 


\section{Key points}

- Most childcare centers were aware of the new Booster Law, yet only half felt they would be compliant by the time the law took effect.

- Centers that were aware and knowledgeable about the law, and felt comfortable advocating for booster seat use, were more likely to be compliant.

- Lack of booster seats, as well as insufficient knowledge about the law, were the greatest barriers to compliance.

- Effective booster seat promotion education will address cost and knowledge barriers related to compliance.

returned our survey may be more proactive in advocating for child safety than non-respondents, and our findings could under-represent the possible predisposing and enabling factors to compliance.

\section{IMPLICATIONS FOR PREVENTION}

This study has provided important information regarding the factors associated with childcare providers' compliance with the new booster seat law. This knowledge can be applied to prevention campaigns, as research has suggested that childcare centers offer opportunities for effective health promotion and injury prevention education. ${ }^{14}{ }^{16}$ Childcare centers are in a unique position to use policy and programming to influence the norms regarding child safety, and increase the saliency of injury prevention messages to parents. Providers can be important conduits of child safety information to parents, and we believe their support and compliance with the booster seat law will facilitate wider adoption of booster seat use in young school age children. We anticipate that these results will have wider application, as 13 other states have already begun to follow Washington's lead in passing booster seat laws.

\section{ACKNOWLEDGEMENTS}

Supported by funding from the National Highway Traffic Safety Administration.

\section{Authors' affiliations}

B A Chang, Harborview Injury Prevention and Research Center, University of Washington

B E Ebel, Department of Pediatrics and Harborview Injury Prevention and Research Center, University of Washington

F P Rivara, Departments of Pediatrics and Epidemiology and the Harborview Injury Prevention and Research Center, University of

Washington

\section{REFERENCES}

1 Winston F, Durbin D, Kallan M, et al. The danger of premature graduation to seatbelts for young children. Pediatrics 2000;105:1179_ 83

2 Cody B, Mickalide A, Paul H, et al. Child passengers at risk in America: a national study of restraint use. Washington: DC, National SAFE KIDS Campaign, 2002

3 Anton Skeen Act: An Act Relating to Child Passenger Restraint Systems, Revised Code of Washington, 2001.

4 Minimum licensing requirements for child day care centers. Chapter 388-150 Washington Administrative Codes, 1993.

5 Edwards $\mathbf{P}$, Roberts I, Clarke $M$, et al. Methods to influence response to postal questionnaires (Cochrane Methodology Review). The Cochrane Library, issue 1, 2002. Oxford: Update Software.

6 Salant P, Dillman DA. How to conduct your own survey. New York: John Wiley, 1994: 232.

7 Green L, Kreuter M. Health promotion planning: and educational and ecological approach. Mountain View: Mayfield Publishing Company, 1999. 2000;106:e20

8 Rivara F, Bennett E, Crispin B, et al. Booster seats for child passengers: lessons for increasing their use. Inj Prev 2001;7:210-13.

9 Ramsey A, Simpson E, Rivara F. Booster seat use and reasons for nonuse. Pediatrics 2000;106:e20.

10 Bandura A. Self-efficacy: the exercise of control. New York: Freeman \& Co, 1997.

11 Economic Research Service. Measuring rurality: rural-urban continuum codes. Vol. 2002: US Department of Agriculture, 2002.

12 STATA Corporatation. STATA statistical software:release 7.0. College Station, TX: STATA Corporation.

13 US Department of Transportation, National Highway Traffic Safety Administration. A parent's guide to booster seats (available online at www.nhtsa.dot.gov/people/injury/childps/booster_seat/pagel.html).

14 Stuy M, Green M, Doll J. Child care centers: a community resource for injury prevention. J Dev Behav Pediatr 1993;14:224-9.

15 Schrager L, Miller MG. Licensed child care in Washington State: 2000 Olympia: Department of Social and Health Services, 2002.

16 Tripp MK, Herrmann NB, Parcel GS, et al. Sun protection is fun! A skin cancer prevention program for preschools. J Sch Health 2000;70:395-401.

\section{LACUNAE}

\section{Children's poems}

Walking to school is cool Walking to school is fun, It keeps you fit and healthy And you can play, skip and run. You can talk to your Mum, You can enjoy the sun, You can meet your friends, And have great fun.

Aalia, Parkfield Junior and Infant School, Birmingham, UK

Its lots of fun

Stretch your legs and have a run

Though take your time, keep in line

When you're in the walking bus.

Follow the code, look both ways when you cross the road.

It's good for your health,

You're very safe and you won't have a crash,

Walk to school - that's what I call COOL.

Fae, Kings Norton Primary School, Birmingham, UK 